\title{
Flow Characteristics over a Gravel Bedform: Kaj River Case Study
}

\author{
Mohammad Reza MADDAHI ${ }^{1}$, Hossein AFZALIMEHR ${ }^{2}$, \\ and Paweł M. ROWINSKI ${ }^{3}$ \\ ${ }^{1}$ Shahid Bahonar University of Kerman, Department of Water Engineering, \\ Kerman, Iran; e-mail: mreza_maddahi@yahoo.com \\ ${ }^{2}$ Isfahan University of Technology, Department of Water Engineering, \\ Isfahan, Iran \\ ${ }^{3}$ Institute of Geophysics, Polish Academy of Sciences, Warszawa, Poland
}

\section{Abstract}

The present study deals with the turbulence structure in order to better understand the interaction of bedform and flow characteristics in a gravel-bed river. Data measured above a bedform is used to analyze the importance of coherent structures in turbulent transfer. The Reynolds stress and turbulence intensity in stream-wise direction illustrate significant difference along the bedform, showing a three-layer distribution at the crest and a convex one at the downstream of bedform. Quadrant analysis technique is used to picture momentum exchange above the considered bedform and to find the dominant event in bursting process of the gravel bedform. Quadrant analysis demonstrates that the mechanisms of bedforms generation in sand and gravel-bed rivers are similar and sweep is the dominant event in both rivers.

Key words: turbulence, bedform, gravel-bed river, quadrant analysis, Reynolds stress. 


\section{INTRODUCTION}

The flow over a three-dimensional bedform is highly non-uniform, accelerating over upstream slope due to convergence and decelerating over trough due to expansion. In general, bedform formation causes flow separation at the crest, creating a large recirculation zone at the downstream of the bedform (Ferraro and Dey 2015). Recent studies on velocity and turbulence structures over fixed bed in a laboratory flume revealed that: (i) the maximum stream-wise turbulence intensity (root-mean-squared velocity fluctuations) occurred within the flow separation zone and downstream of the reattachment point, (ii) the maximum vertical turbulence intensity occurred along the shear layer within and above the flow separation zone; and (iii) the maximum Reynolds stresses occurred within the separation zone along the shear layer (Bennett and Best 1995). Their quadrant analysis showed that ejection events dominated the shear stress contribution along the local shear layer and sweep events played a significant role near the reattachment point and close to the dune crest.

In coarse-bed rivers, because of a broad range of grain sizes, from sand particles to large boulders, selective transport processes and armoring of the bed surface may occur locally (Church 2015, van Rijn 1993). Thus it is difficult to distinguish a specific kind of bedform; therefore, investigation of the effects of bedforms on flow characteristics is hard and complicated in coarse-bed streams (e.g., Radecki-Pawlik et al. 2006, Carling and Shvidchenko 2002, Dey 2014). Also, typology and kinetic behavior of gravel-bed forms are not well understood at all (Qin et al. 2015). Some studies have been conducted in gravel-bed streams to understand the effects of gravel size on turbulence intensity and Reynolds stress (e.g., Dey and Raikar 2007). It seems that the mountain rivers with a gentle slope which are located in central and northern Iran are suitable for such studies; it turns out that it is possible to determine relevant bedforms there. The customary definitions based on the mechanics of transport, while useful, are not sufficient to understand river channel deformation; indeed, they may have contributed to limit the understanding (Church 2006). Therefore, more requires to be investigated about flow characteristics in relation to bedforms. Recently an interesting study of turbulent flow field in a gravel-bed river has been performed with use of a novel $2 \mathrm{MHz}$ Acoustic Doppler Beam (ADB) (MacMahan et al. 2012). The aim of this study was to "expand observations of stream-wise length scales of macroscale coherent flow structures in deeper and faster flow under a variety conditions in a natural gravel-bed river". They measured macroscale turbulence features behind a large river obstacle and revealed that understanding of flow structure plays a significant role in modeling of sediment transport in gravel-bed rivers (MacMahan et al. 2012). 
Some scientists revealed that rivers with different geometric scales affect the flow characteristics and turbulence; they found that the spatial scales which are due to bedforms, influence turbulence generation and flow field characteristics including velocity and Reynolds stress distributions (Franca and Brocchini 2015). The presence of rough bedforms, which is typical for river flows, influences local velocity field, and flow structure. Although the subject of river turbulence has been on the agenda for more than a century, that issue has not been studied sufficiently. Therefore, a proper understanding of river turbulence is essential to many aspects of river engineering, including environmental hydraulics and eco hydraulics (Nikora 2010).

This study presents an example of field investigations which allows gaining some more understanding of flow patterns above bedforms in gravel-bed rivers.

\section{DATA COLLECTION}

In this study, field data were collected in the Kaj River in Chaharmahal and Bakhtiari province in central Iran. This river originates from the Koohrang Mountains and then discharges into the Karoon River. The regime of this river is snow melting. In this study, one straight reach with no vegetation in banks and in riverbed was selected with a length of $32 \mathrm{~m}$ and an average width of $25 \mathrm{~m}$. There was no boulder in the selected reach to pertubate the flow characteristics along the reach. After selecting the study reach and conducting initial surveying of the river bed, a bedform along the reach was selected. Due to logistic restrictions, only three cross-sections were considered (one at the crest of bedform and two others at the lee side) to obtain the hydraulic parameters of flow, namely flow velocity distribution, flow depths, water surface slope, particle sizes, Reynolds stresses and turbulence intensities. The discharge within the selected river reach during data collection was about $7 \mathrm{~m}^{3} / \mathrm{s}$. Figure 1 illustrates the selected reach and its geographic position.

Grain size of bed material was obtained using Wolman pebble counts (Wolman 1954). At each cross-section, three patches were chosen at the left bank, right bank and the center of the cross-section. In each patch, for an area of $1 \mathrm{~m} \times 1 \mathrm{~m}, 100$ grains were collected randomly and median diameter of each grain was measured by a caliper.

The Acoustic Doppler Velocimeter (ADV) was mounted on a table with dimensions of $1.5 \mathrm{~m} \times 0.7 \mathrm{~m}$. To make the ADV exactly vertical to the water surface, it was hanged from a horizontal triangular iron plate which was leveled using three screws. In Fig. 2 the table and the leveled plate are shown. 

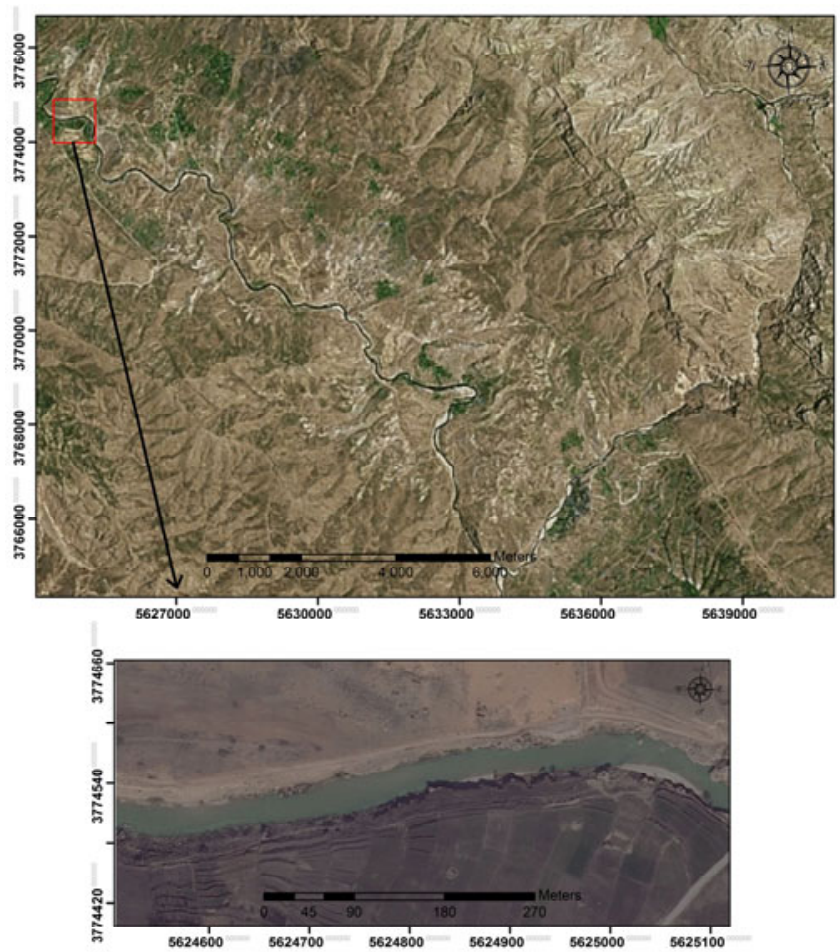

Fig. 1. Geographic map of the river and selected reach.
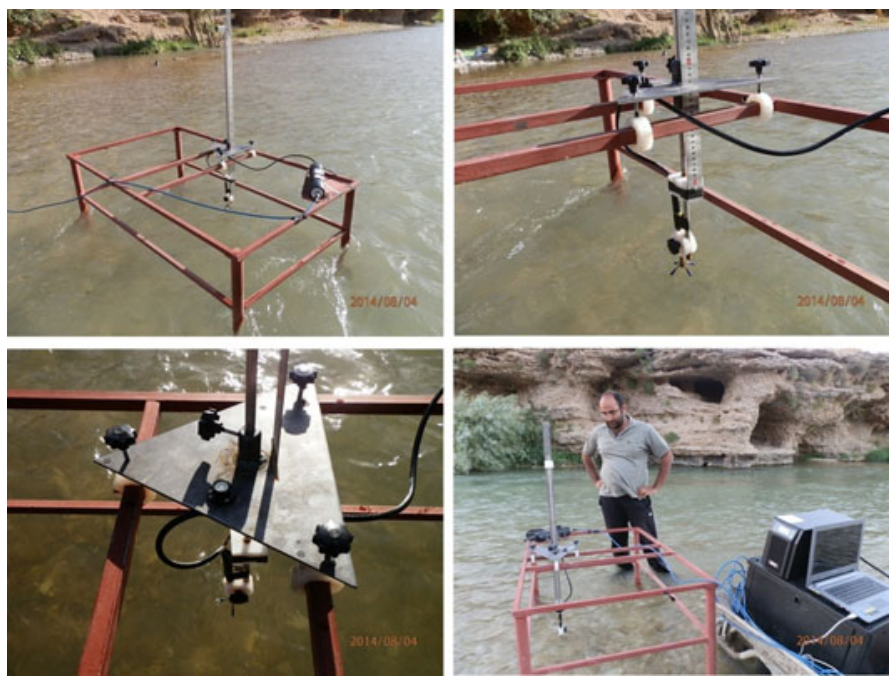

Fig. 2. The table that ADV had been mounted. 
The ADV with a sampling rate of $200 \mathrm{~Hz}$ and sampling duration of $120 \mathrm{~s}$ was used to measure the velocity profiles. During data sampling, the flow was assumed steady and non-uniform. To obtain high quality data from the time series, ADV velocity data were filtered by the Goring and Nikora algorithm (Goring and Nikora 2002). At each cross-section, 4 velocity profiles were measured. For each velocity profile, depending on water depth, 11 to 17 point velocities were measured. For $y / H<0.2 H$ (where $y$ is the vertical distance from the bed and $H$ is the water depth) the measurements of $y$ were carried with a distance interval of $5 \mathrm{~mm}$; however, for $y / H>0.2$, the vertical distance of measurements became more than $5 \mathrm{~mm}$.

Topography of the river reach, channel bed and water surface slopes were surveyed using a Leica total station camera (TC 1700) with the accuracy of 1.7". In order to minimize equipment errors, the camera was located in a place where the distance to upstream end of the reach was equal to the distance to downstream end of it. To increase the accuracy of the operation, a large number of data were surveyed along the bed. For this purpose, ropes were used over water surface to set up a network for the measurements of river bed. The grids of the network had dimensions of $1 \mathrm{~m} \times 1 \mathrm{~m}$. By using this network, the average point density was about 1.2 points per square meters. After taking data, the bathymetry of the river reach was obtained from a point-based Triangular Irregular Network (TIN) and then the river bed profile was plotted.

\section{RESULTS AND DISCUSSIONS}

Based on field measurements of the river bed, the longitudinal profile of bed can be presented. In this way, the bedform is detectable and its dimensions are measured in details. Figure 3 displays the bedform, the water surface elevation and the measured velocity profiles along the selected reach.

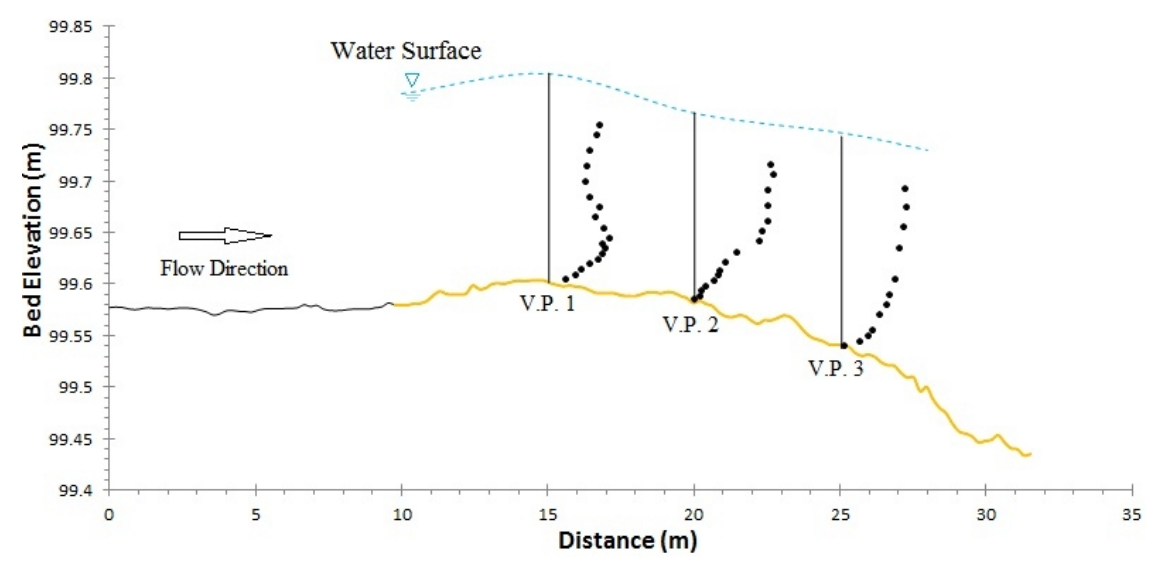

Fig. 3. Selected bedform, water surface, and velocity profiles. 
The distance between the crest of the bedform and the point of reattachment is the length of the separation zone. The ratio of the length of separation to the length of bedform is a function of Froude number (Karahan and Peterson 1980; Fig. 4).

Figure 4 illustrates that for small values of Froude number, less than 0.2, the ratio of separation length $(L)$ to the length of bedform $(\lambda)$ decreases sharply with increasing Froude number and then it approaches a constant value of 0.32 for Froude number larger than 0.2. To determine the Froude number over the selected bedform, the double-averaging method (DAM) is used to calculate average flow velocity. Double-averaging method (DAM) allows characterizing three-dimensional flows over irregular boundaries and it has extensive roots in multi-phase flow and porous-media hydrodynamics (Nikora and Rowiński 2008). Each point flow velocity in a profile is the time average velocity of 24000 data using the frequency of $200 \mathrm{~Hz}$ and 2 minutes sampling period. The spatial average is also the average of velocities having equal distance from the river bed. Recent studies applied the doubleaveraging method for an artificial pool in laboratory to calculate mean velocity, shear velocity, the Froude and Reynolds numbers over a pool (Fazlollahi et al. 2015). They found that at the downstream of crest, the stream-wise velocity decreases when the angle of slope of pool entrance increases and flow separation is observed (Fazlollahi et al. 2015). Also, the shear stress values increase with increasing entrance slope (Fazlollahi et al. 2015). Although they conducted their research for small aspect ratio $(W / h<5$ where $W$ is the

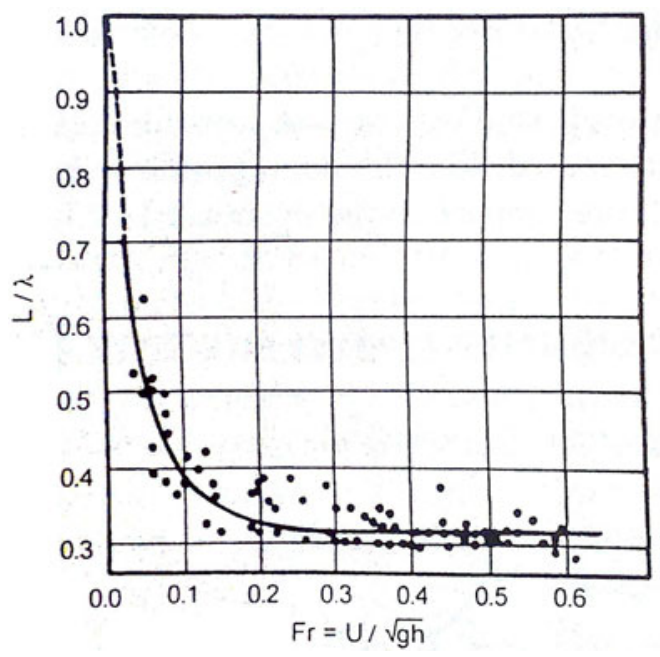

Fig. 4. Relationship between length of recirculation zone and flow conditions (Karahan and Peterson 1980). 
width and $h$ is the flow depth), they did not observe dip phenomena in which the maximum velocity occurs under the water surface, but found a convex distribution for Reynolds stress (Fazlollahi et al. 2015).

In order to compare the results of the present study with Fazlollahi et al.'s study, DAM is applied, although we do realize that relatively little data makes this averaging procedure error-burdened. Using the following Eqs. 1 and 2, the double-averaged velocity for each depth is calculated:

$$
\begin{gathered}
\left\langle\bar{V}_{t}\right\rangle=\frac{\sum_{i=1}^{n} u_{t i}}{n}, \\
\left\langle\bar{V}_{s}\right\rangle=\frac{\sum_{j=1}^{m}\left\langle V_{t}\right\rangle_{j}}{m},
\end{gathered}
$$

where $\bar{V}_{t}$ is the time-average velocity for each depth, $n$ is the number of velocity data, $u_{t}$ is the measured point velocity, $m$ is the number of velocity profiles over the bedform which is equal to 3 in this study and $\bar{V}_{s}$ is the spatially-average velocity along the bedform. Using double-averaging method, the new velocity profile averaged over the reach representing the whole bedform is shown in Fig. 5.

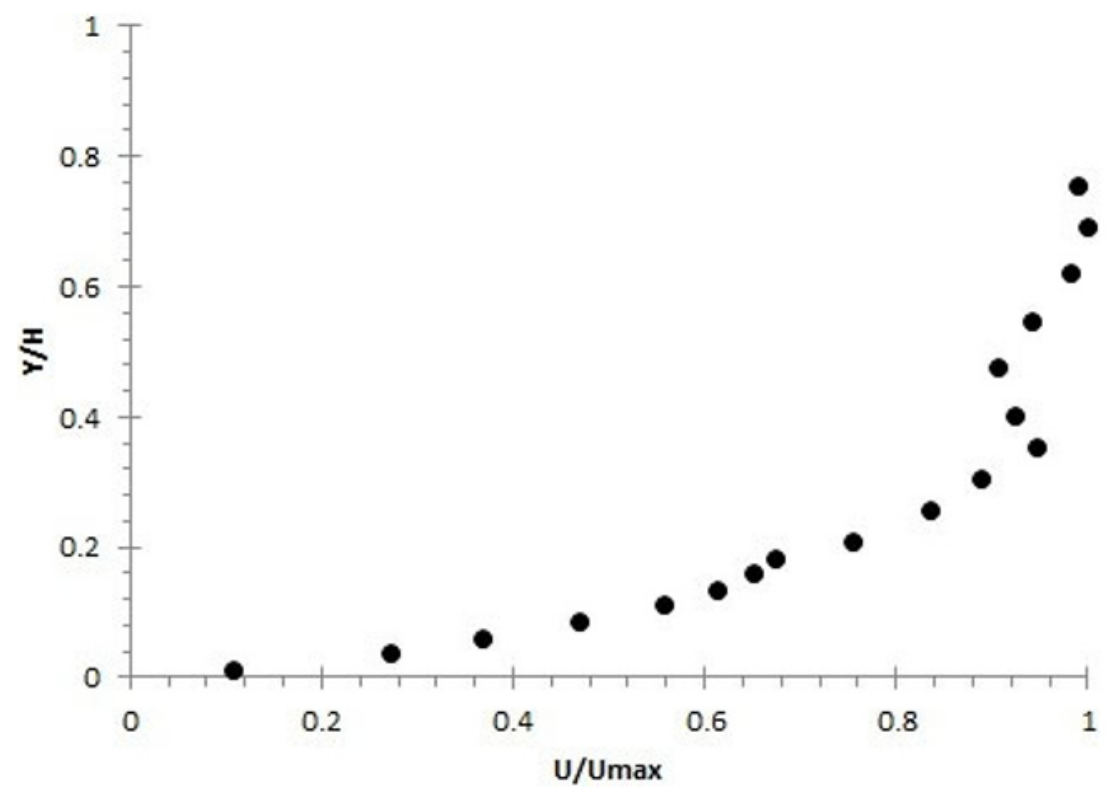

Fig. 5. Double-averaging velocity profile over the bedform. 
Then the Froude number can be calculated as follows:

$$
F r=\frac{\left\langle\bar{V}_{s}\right\rangle}{\sqrt{g H}},
$$

where $g$ is the gravitational acceleration, and $H$ is the average depth over bedform. The Froude number over the bedform is 0.28 and according to Karahan and Peterson's diagram, the ratio of the length of separation zone to the length of the bedform is 0.32 . Since the length of bedform is $21.75 \mathrm{~m}$, the length of separation would be $7 \mathrm{~m}$, showing that the velocity near the river bed for the second velocity profile should present negative values because this velocity profile was measured inside the separation zone. Figure 3 does not display the adverse flow, showing that the separation zone is not detectable by ADV over this bedform; however, the velocity distribution is nonuniform within the crest and its shape is S-like, showing the presence of inflection point which is necessary for the occurrence of separation. Also the contour lines of velocity in the direction of flow illustrate that stream lines of the flow are parallel to the river bed (Fig. 6).

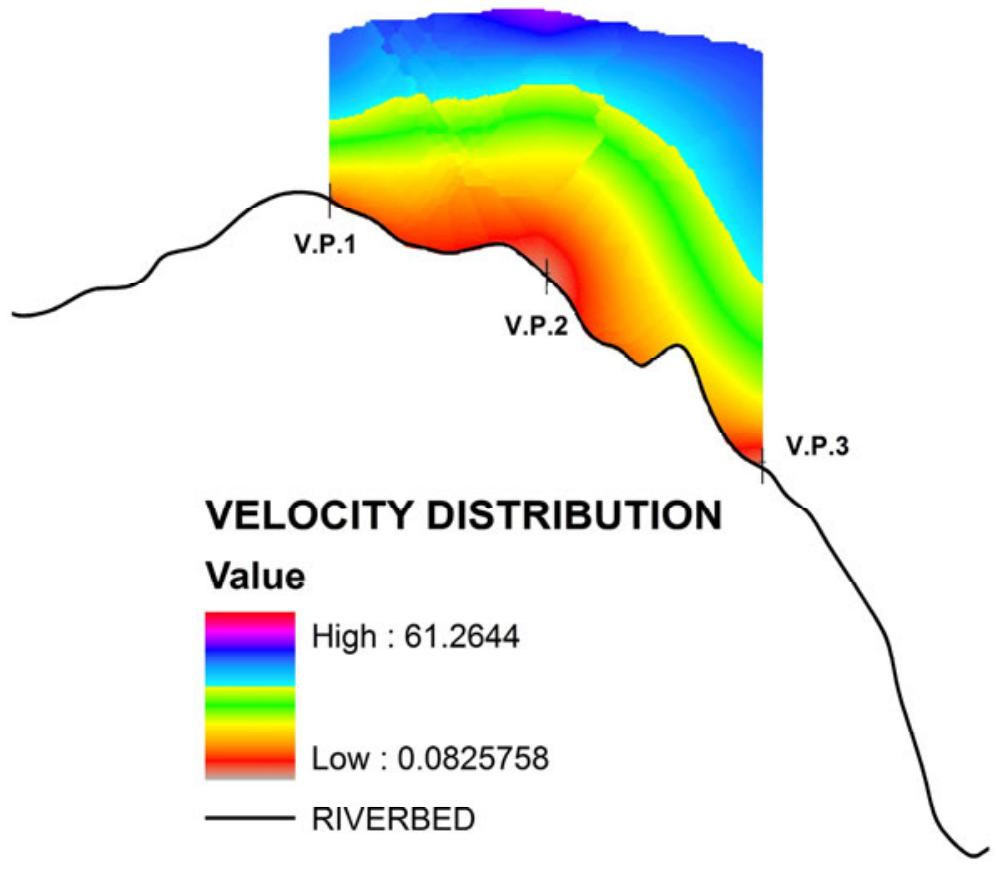

Fig. 6. Stream lines of flow over the bedform. 


\section{TURBULENCE STRUCTURE OVER GRAVEL BEDFORMS}

Structure of turbulence over bedforms is complicated and the flow consists of a number of different spatial regimes which are interacted by bed geometry (Bialik et al. 2014, McLean and Smith 1986, Nikora et al. 1997). Rivers with gravel bedforms have received relatively little attention (Shvidchenko and Pender 2001). Therefore, this study is supposed to start filling this knowledge gap although it is a very preliminary approach. The basic characteristics of turbulence that are considered herein are time-averaged streamwise velocity, $\bar{u}$, span-wise mean velocity, $\bar{v}$, vertical mean velocity, $\bar{w}$, stream-wise turbulence intensity, $\sqrt{\overline{u^{\prime 2}}}$, span-wise turbulence intensity, $\sqrt{\overline{v^{\prime 2}}}$, and vertical turbulence intensity, $\sqrt{\overline{w^{\prime 2}}}$, which are defined as:

$$
\begin{gathered}
\bar{u}=\sum_{i=1}^{N} \frac{u_{i}}{N} \\
\bar{v}=\sum_{i=1}^{N} \frac{v_{i}}{N} \\
\bar{w}=\sum_{i=1}^{N} \frac{w_{i}}{N} \\
\sqrt{\overline{u^{\prime 2}}}=\sum_{i=1}^{N} \sqrt{\frac{\left(u_{i}-\bar{u}\right)}{N-1}} \\
\sqrt{\overline{v^{\prime 2}}}=\sum_{i=1}^{N} \sqrt{\frac{\left(v_{i}-\bar{v}\right)}{N-1}} \\
\sqrt{\overline{w^{\prime 2}}}=\sum_{i=1}^{N} \sqrt{\frac{\left(w_{i}-\bar{w}\right)}{N-1}}
\end{gathered}
$$

where $N$ is the number of time series values equal to 24000 in this study. The time-averaged local Reynolds shear stress at a point is determined using the equation:

$$
\tau=-\rho \overline{u^{\prime} w^{\prime}}
$$

where

$$
\overline{u^{\prime} w^{\prime}}=\sum_{i=1}^{N} \sqrt{\frac{\left(u_{i}-\bar{u}\right)\left(w_{i}-\bar{w}\right)}{N-1}}
$$


In the above equations, the prime denotes velocity fluctuations and $\rho$ is water density.

Figure 7 shows the normalized Reynolds stress and turbulence intensity using shear velocity $\left(u_{*}\right)$. There are numerous methods to evaluate the bed shear velocities and we realize that they are particularly troublesome in unsteady and non-uniform flows (see, e.g., Mrokowska et al. 2015).
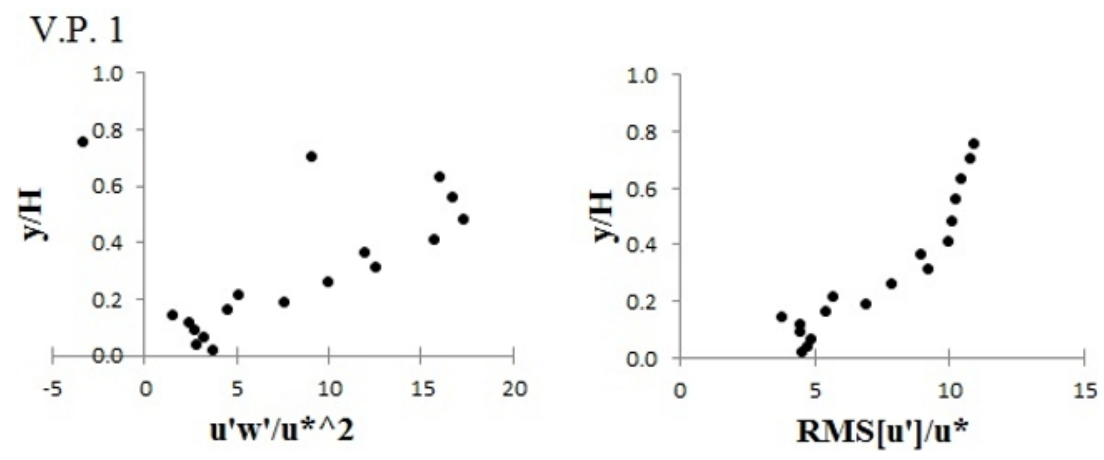

\section{V.P. 2}
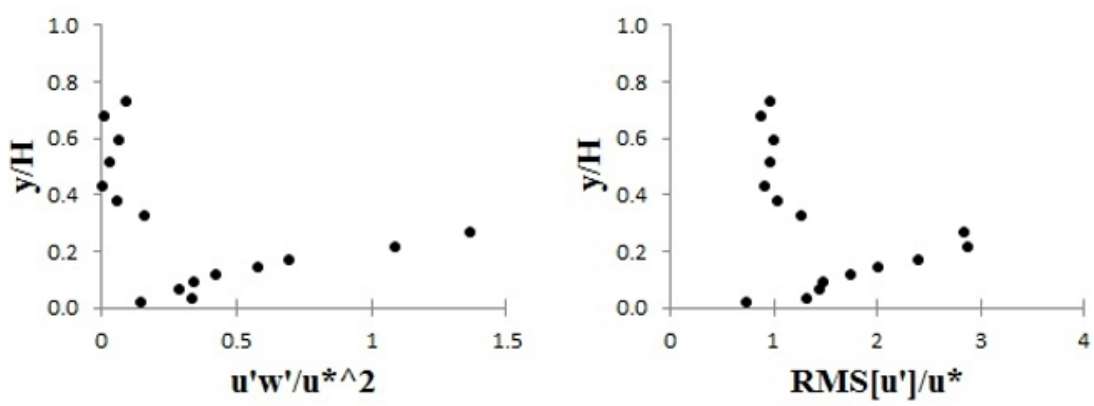

V.P. 3
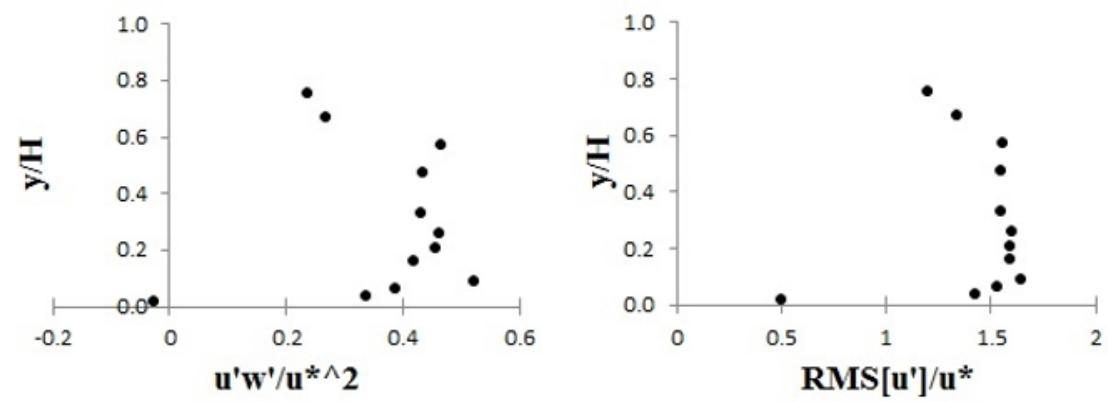

Fig. 7. Turbulence intensity and Reynolds stress along the bedform. 
In this study the shear velocity was determined by the boundary-layer characteristics method (BLCM) (Afzalimehr and Anctil 2000). This method uses velocity distribution and is presented as:

$$
u_{*}=\frac{\left(\delta_{*}-\theta\right) u_{\max }}{\alpha \delta_{*}},
$$

where $\alpha$ is a constant that has to be evaluated based on flow conditions. Using both laboratory and field data, the value of $\alpha=4.4$ was applied in this study (Afzalimehr and Anctil 2000, Afzalimehr and Rennie 2009), $u_{\max }$ is the maximum velocity observed in a velocity profile, $\delta_{*}$ is the displacement thickness and $\theta$ is the momentum thickness. These thicknesses are defined as (Schlichting and Geresten 2000):

$$
\begin{gathered}
\delta_{*}=\int_{0}^{h}\left(1-\frac{u}{u_{\max }}\right) d y, \\
\theta=\int_{0}^{h} \frac{u}{u_{\max }}\left(1-\frac{u}{u_{\max }}\right) d y .
\end{gathered}
$$

Figure 7 shows clearly that the distributions of Reynolds stress and turbulence intensity in stream-wise direction depend on the location of the measuring profile, i.e., whether it is above the crest, the stoss or the lee. Above the crest, a three-layer distribution for the Reynolds stress is observed whereas it has a two-layer form with regard to turbulence intensity. The first layer observed near the bed is not visible on the flat gravel-bed (Graf and Altinakar 1993, Afzalimehr 2010). It is because an internal boundary layer forms near the bedform and it does not exist over the flat bed. In addition, the turbulence intensity distribution over gravel-bed follows the Reynolds stress one, revealing two layers, the first layer with increasing trend near the bed and the second one with decreasing trend towards the water surface. Such a distribution is not observed over the bedform at the crest section (V.P.1 in Fig. 3). At the location of V.P.2, a considerable change is observed in comparison with V.P.1. However, by moving to location of V.P.3, no inflection point is observed, showing similar distributions for velocity, Reynolds stress and turbulence intensity to the one over flat gravel-bed.

Turbulence spectra in river flows exhibit a $-5 / 3$ roll off at high frequencies (Nikora et al. 1994, Venditti and Bauer 2005). It concerns the range where no energy production or dissipation occurs.

In some studies, it is observed that in the transition between the crest and the lee, the spectral peaks in $v$ and $w$ are shifted to higher frequencies than in the $u$ spectrum and this shift persists downstream in the wake zone (Venditti and Bauer 2005). Observations of Venditti and Bauer applied to an alluvial 
reach of a river, while our study considers carefully a reach where a pool and a riffle exist. The results show that the law of $-5 / 3$ is not universal for different distances from the bed at the crest of riffle, the downstream of riffle (lee zone), and the pool zone for all frequencies. At the crest and pool cases near the water surface $u$ and $v$ do not follow this law, especially at high frequencies. When water leaves the pool and approaches the following riffle (stoss
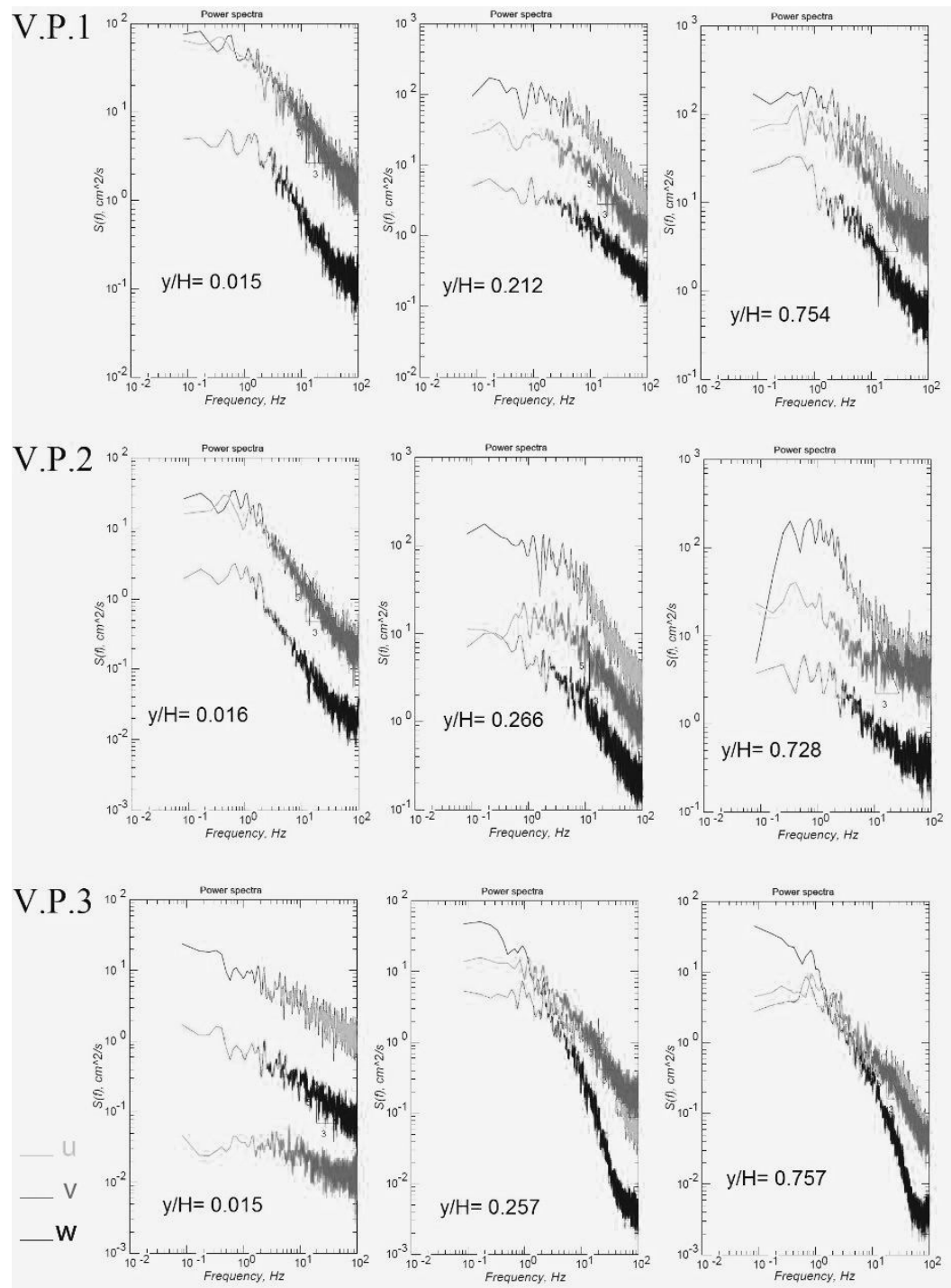

Fig. 8. Spectral analysis at different parts of the bedform (span-wise direction is $v$ and vertical direction is $w$ ). 
zone), the law of $-5 / 3$ is observed for all frequencies except for $y / H=0.728$ at crest, showing much more horizontal spectra for $u$ and $v$ velocity components (see Fig. 8). This result shows that the law of $-5 / 3$ is not held herein since the Kolmogorov scale is not necessarily an eddy scale and the flow field is not in equilibrium.

\section{QUADRANT ANALYSIS}

It is of crucial importance to identify coherent structures within the flow which is possible by isolating the contributors to the Reynolds shear stresses. Those coherent structures are responsible for production of turbulent kinetic energy; they also play an important role in the mechanism of sediment entrainment. It is customary to plot $u^{\prime}$ and $w^{\prime}$ according to quadrant in the $u^{\prime} w^{\prime}$-plane (Lu and Willmarth 1973). The so-called quadrant analysis enables detecting both organized (ejections and sweeps) and unorganized counterflux events. Figure 9 presents the results of quadrant analysis for 3 velocity profiles.

Accordingly, sweep and ejection are the most common events in crest and lee side of the selected bedform in gravel-bed river. Other studies have also revealed that these events are the dominant ones in rough bed channels (Nasiri et al. 2011, Nezu et al. 1994, Thorne et al. 1989). The results of quadrant analysis for an artificial pool showed that for small and large entrance slopes, sweep and ejection were dominant events, while the outward and inward events have the shorter time fraction and the smaller values of the shear stress than the absolute values of the sweep and ejection (Fazlollahi et al. 2015). As sweep and ejection play a great role in sediment transport, one can conclude that from crest to downstream side of bedform, the rate of bed load transport over the bedform is more significant than the rate of suspended load transport. Since the formation of sand waves in rivers is due to bed load transport, sweep event plays a vital role in sand bedform generation; on the other hand, the similarities in coherent structures over the selected bedform and over sand waves reveal that the mechanism of formation of bedforms in coarse-bed rivers (sand and gravel-bed rivers) is the same as sand waves. In other studies on bedforms in flumes, the probability of sweep event was greater than that of other events, and ejection, outward and inward, was in later order, respectively (Cellino and Lemmin 2004). The order is the same for lee side of the selected bedform; however, by moving from the crest to the upstream of the bedform, the other event (outward) contributes more in the bursting process.

Figure 9 clearly reveals that the distributions of four events (the outward, ejection, the inward and sweep) are different in V.P.1 and V.P.3, showing 

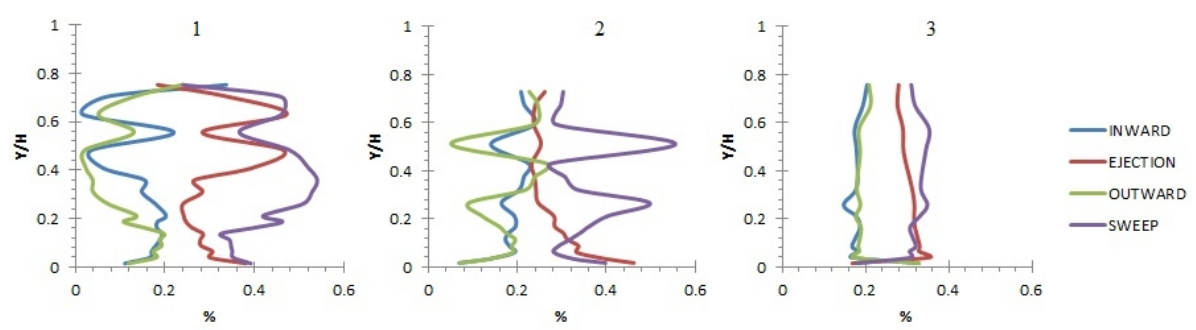

Fig. 9. Quadrant analysis for 3 velocity profiles over the bedform.

considerable variation from the bed to the water surface for V.P.1, while a uniform distribution is observed for V.P.3.

Based on the results of the present study and the existing studies over the bedforms in laboratory (Bennett and Best 1995, Nasiri et al. 2013), the following comparison can be presented: The time-averaged vertical velocity upstream of the sand dune crest was zero or negative near the water surface, but it was positive for sharp-crested gravel bedforms and the selected bedform in this study. Maximum values of RMS $u$ over sharp-crested gravel bedforms were located far from the bed when they were compared to those over sand dunes. However, Fig. 7 shows that the maximum values of RMS $u$ occur near the bed for the crest and downstream of the bedform. The Reynolds stresses were zero or negative near the water surface over sand dunes, while they were positive over sharp-crested gravel bedforms; however, the Reynolds stress distributions over the bedform in the gravel bedform do not reveal similar pattern along the bedform, although the positive values are dominant in all parts of bedforms, including the downstream region.

\section{CONCLUSIONS}

Results of this study show that there are considerable differences between the flow characteristics over two-dimensional bedforms in laboratory scale and three-dimensional ones over gravel-bed rivers.

Results of quadrant analysis show that the mechanisms of bedforms generation in sand and gravel-bed rivers are similar. In both rivers the dominant event is sweep showing the crucial role of bed load transport in bedform formation.

ADV cannot detect clearly the separation zone in gravel-bed rivers; however, the presence of S-shape velocity profile reveals the inflection point at the crest section which is a sign of existing separation zone.

The Reynolds stress and turbulence intensity in stream-wise direction illustrate significant difference along the bedform, showing a three-layer distribution at the crest and a convex one at the downstream of bedform. 
Similar distribution between downstream of bedform (lee region) and the flat gravel-bed was observed in this study.

Complex distributions of Reynolds stress and turbulence intensity along a bedform call to investigate the gravel bedforms with more details in threedimensional at laboratory scale in order to better understand the interaction of flow and the river bed.

Turbulence spectra show that the law of $-5 / 3$ is not universal since the Kolmogorov scale is not necessarily an eddy scale and the flow field is not in equilibrium.

The results presented above are of preliminary character and due to relatively scarce data we do not claim they are of universal character.

Acknowledgments. This work has been partially supported by the statutory funds of the Institute of Geophysics, Polish Academy of Sciences.

\section{References}

Afzalimehr, H. (2010), Effect of flow non-uniformity on velocity and turbulence intensities in flow over a cobble-bed, J. Hydrol. Proc. 24, 3, 331-341, DOI: 10.1002/hyp.7495.

Afzalimehr, H., and F. Anctil (2000), Accelerating shear velocity in gravel bed channels, J. Hydrol. Sci. 45, 1, 113-124, DOI: 10.1080/ 02626660009492309.

Afzalimehr, H., and C.D. Rennie (2009), Determination of bed shear stress using boundary layer parameters in a gravel-bed river, J. Hydrol. Sci. 54, 1, 147159, DOI: $10.1623 /$ hysj.54.1.147.

Bennett, S.J., and J.L. Best (1995), Mean flow and turbulence structure over fixed, two-dimensional dunes: implications for sediment transport and bed form stability, Sedimentology 42, 3, 491-513, DOI: 10.1111/j.1365-3091.1995. tb00386.x.

Bialik, R., M. Karpinski, A. Rajwa, B. Luks, and P.M. Rowinski (2014), Bedform characteristics in natural and regulated channels: a comparative field study on the Wilga River, Poland, Acta Geophys. 62, 6, 1413-1434, DOI: 10.2478/s11600-014-0239-0.

Carling, P.A., and A.B. Shvidchenko (2002), A consideration of the dune:antidune transition in fine gravel, Sedimentology 49, 6, 1269-1282, DOI: 10.1046/ j.1365-3091.2002.00496.x.

Cellino, M., and U. Lemmin (2004), Influence of coherent flow structures on the dynamics of suspended sediment transport in open-channel flow, $J$. Hydraul. Eng. ASCE 130, 11, 1077-1088, DOI: 10.1061/(ASCE)0733-9429 (2004)130:11(1077). 
Church, M. (2006), Bed material transport and the morphology of alluvial river channels, Ann. Rev. Earth Planet. Sci. 34, 325-354, DOI: 10.1146/annurev. earth.33.092203.122721.

Church, M. (2015), Channel stability: morphodynamics and the morphology of rivers. In: P.M. Rowiński and A. Radecki-Pawlik (eds.), Rivers-Physical, Fluvial and Environmental Processes, Springer, Switzerland, 281-321, DOI: 10.1007/978-3-319-17719-9 2.

Dey, S. (2014), Fluvial Hydrodynamics: Hydrodynamic and Sediment Transport Phenomena, Springer, Berlin Heidelberg, DOI: 10.1007/978-3-642-19062-9.

Dey, S., and R. Raikar (2007), Characteristics of loose rough boundary streams at near-threshold, J. Hydraul. Eng. ASCE 133, 3, 288-304, DOI: 10.1061/ (ASCE)0733-9429.

Fazlollahi, A., H. Afzalimehr, and J. Sui (2015), Effect of slope angle of an artificial pool on distributions of turbulence, Int. J. Sed. Res. 30, 2, 93-99.

Ferraro, D., and S. Dey (2015), Principles of mechanics of bedforms. In: P.M. Rowiński, and A. Radecki-Pawlik (eds.), Rivers-Physical, Fluvial and Environmental Processes, Springer, Switzerland, 79-98, DOI: 10.1007/978-3319-17719-92.

Franca, M.J., and M. Brocchini (2015), Turbulence in rivers. In: P.M. Rowiński and A. Radecki-Pawlik (eds.), Rivers-Physical, Fluvial and Environmental Processes, Springer, Switzerland, 51-78, DOI: 10.1007/978-3-319-17719-9 2.

Goring, D., and V.I. Nikora (2002), Despiking acoustic doppler velocimeter data, J. Hydraul. Eng. ASCE 128, 1, 117-126, DOI: 10.1061/(ASCE)07339429(2002)128:1(117).

Graf, W.H., and M.S. Altinakar (1993), Hydraulique fluviale: écoulement et phénomènes de transport dans les canaux a géométrie simple, Presses Polytechniques et Universitaires Romandes, Lausanne, Switzerland.

Karahan, M.E., and A.W. Peterson (1980), Visualization of separation over sand waves, J. Hydraul. Div. ASCE 106, 8, 1345-1352.

Lu, S.S., and W.W. Willmarth (1973), Measurements of the structure of the Reynolds stress in a turbulent boundary layer, J. Fluid. Mech. 60, 3, 481-511, DOI: http://dx.doi.org/10.1017/S0022112073000315.

MacMahan, J., A. Reniers, W. Ashley, and E. Thornton (2012), Frequency wavenumber velocity spectra, Taylor's hypothesis and length scales in a natural gravel bed river, Water. Resour. Res. 48, W09548, DOI: 10.1029/ 2011WR011709.

McLean, S.R., and J.D. Smith (1986), A model for flow over two dimensional bedforms, J. Hydraul. Eng. ASCE 112, 4, 300-317, DOI: http://dx.doi.org/ 10.1061/(ASCE)0733-9429(1986)112:4(300).

Mrokowska, M., P.M. Rowiński, and M.B. Kalinowska (2015), A methodological approach of estimating of resistance to flow under unsteady flow condi- 
tions, Hydrol. Earth Syst. Sci. 19, 4041-4053, DOI: 10.5194/hess-19-40412015.

Nasiri, E., H. Afzalimehr, and V.P. Singh (2011), Effect of bed forms and vegetated banks on velocity distributions and turbulent flow structure, J. Hydrol. Eng. ASCE 16, 6, 495-507, DOI: 10.1061/(ASCE)HE.1943-5584.0000337.

Nasiri, E., H. Afzalimehr, J. Gallichand, and A.N. Rousseau (2013), Turbulence measurements above sharp-crested gravel bedforms, Int. J. Hydraul. Eng. 2, 5, 101-114, DOI: 10.5923/j.ijhe.20130205.04.

Nezu, I., H. Nakagawa, and G. Jirka (1994), Turbulence in open-channel flows. J. Hydraul. Eng. ASCE 120, 10, 1235-1237, DOI: http://dx.doi.org/10.1061/ (ASCE)0733-9429(1994)120:10(1235).

Nikora, V.I. (2010), Hydrodynamics of aquatic ecosystems: an interface between ecology, biomechanics and environmental fluid mechanics, River. Res. Appl. 26, 4, 367-384, DOI: 10.1002/rra.1291.

Nikora, V.I., and P.M. Rowiński (2008), Rough-bed flows in geophysical, environmental, and engineering systems: double-averaging approach and its applications, Acta Geophys. 56, 3, 529-533, DOI: 10.2478/s11600-008-0037-7.

Nikora, V.I., P.M. Rowiński, A. Suchodolov, and D. Krasuski (1994), Structure of river turbulence behind warm-water discharge. J. Hydraul. Eng. ASCE 120, 2, 191-208, DOI: 10.1061/(ASCE)0733-9429(1994)120:2(191).

Nikora, V.I., A. Sukhodolov, and P.M. Rowiński (1997), Statistical sand waves dynamics in one-directional water flows, J. Fluid. Mech. 351, 17-39, DOI: 10.1017/S0022112097006708.

Qin, J., T. Wu, and D. Zhong (2015), Spectral behavior of gravel dunes, Geomorphology 231, 331-342, DOI: 10.1016/j.geomorph.2014.12.023.

Radecki-Pawlik, A., P.A. Carling, E. Slowik-Opoka, L. Ksiazek, and R. Breakspeare (2006), Field investigation of sand-gravel bed forms within the Raba River, Poland. In: R.M.L. Ferreira, E.C.T.L. Alves, J.G.A.B. Leal, and A.H. Cardoso (eds.), Proc. Inter. Conference on Fluvial Hydraulics, 6-8 September 2006, Lisbon, Portugal, 979-984.

Schlichting, H., and K. Geresten (2000), Boundary-Layer Theory, Springer, Berlin Heidelberg, DM 179.

Shvidchenko, A.B., and G. Pender (2001), Macroturbulent structure of open-channel flow over gravel beds, Water. Resour. Res. 37, 709-719, DOI: 10.1029/ 2000WR900280.

Thorne, P.D., J.J. Williams, and A.D. Heathershaw (1989), In situ acoustic measurements of marine gravel threshold and transport, Sedimentology 36, 1, 6174, DOI: 10.1111/j.1365-3091.1989.tb00820.x.

van Rijn, L.C. (1993), Principles of Sediment Transport in Rivers, Estuaries and Coastal Seas, Aqua Publications, Amsterdam.

Venditti, J.G., and O.B. Bauer (2005), Turbulent flow over a dune: Green River, Colorado, Earth Surf. Proc. Land. 30, 3, 289-304, DOI: 10.1002/esp.1142. 
Wolman, M.G. (1954), A method of sampling coarse river-bed material. $J . A m$. Geophys. Union 35, 6, 951-956, DOI: 10.1029/TR035i006p00951.

Received 3 November 2015 Received in revised form 17 December 2015 Accepted 27 January 2016 